\title{
Article \\ Aptasensor for the Detection of Mycobacterium tuberculosis in Sputum Utilising CFP10-ESAT6 Protein as a Selective Biomarker
}

\author{
Umi Zulaikha Mohd Azmi ${ }^{1}$ (D), Nor Azah Yusof 1,2,*, Jaafar Abdullah 1,2 (D), Faruq Mohammad ${ }^{3, *(\mathbb{D}),}$ \\ Shahrul Ainliah Alang Ahmad ${ }^{1,2}$, Siti Suraiya ${ }^{4}$, Nurul Hanun Ahmad Raston 5 , Fatin Nabilah Mohd Faudzi ${ }^{1}$, \\ Sachin K. Khiste ${ }^{6}$ and Hamad A. Al-Lohedan ${ }^{3}$
}

check for updates

Citation: Azmi, U.Z.M.; Yusof, N.A.; Abdullah, J.; Mohammad, F.; Ahmad, S.A.A.; Suraiya, S.; Raston, N.H.A.; Faudzi, F.N.M.; Khiste, S.K.;

Al-Lohedan, H.A. Aptasensor for the Detection of Mycobacterium tuberculosis in Sputum Utilising CFP10-ESAT6 Protein as a Selective Biomarker. Nanomaterials 2021, 11, 2446. https://doi.org/10.3390/ nano11092446

Academic Editor: Lyudmila M. Bronstein

Received: 19 August 2021

Accepted: 9 September 2021

Published: 20 September 2021

Publisher's Note: MDPI stays neutral with regard to jurisdictional claims in published maps and institutional affiliations.

Copyright: (C) 2021 by the authors Licensee MDPI, Basel, Switzerland. This article is an open access article distributed under the terms and conditions of the Creative Commons Attribution (CC BY) license (https:/ / creativecommons.org/licenses/by/ $4.0 /)$.
1 Institute of Advanced Technology, Universiti Putra Malaysia, Serdang 43400, Selangor, Malaysia; umizulaikha.ika@gmail.com (U.Z.M.A.); jafar@upm.edu.my (J.A.); ainliah@upm.edu.my (S.A.A.A.); fatinnmf@upm.edu.my (F.N.M.F.)

2 Department of Chemistry, Faculty of Science, Universiti Putra Malaysia, Serdang 43400, Selangor, Malaysia

3 Department of Chemistry, College of Science, King Saud University, P.O. Box 2455,

Riyadh 11451, Saudi Arabia; hlohedan@ksu.edu.sa

4 School of Medical Sciences, Universiti Sains Malaysia, Kubang Kerian, Kelantan 16150, Malaysia; ssuraiya@usm.my

5 School of Biosciences and Biotechnology, Faculty of Science and Technology, Universiti Kebangsaan Malaysia, UKM Bangi 43600, Selangor, Malaysia; nurulhanun@ukm.edu.my

6 Department of Medicine, Harvard Medical School, Boston, MA 02115, USA; skhiste@bwh.harvard.edu

* Correspondence: azahy@upm.edu.my (N.A.Y.); fmohammad@ksu.edu.sa (F.M.)

Abstract: A portable electrochemical aptamer-antibody based sandwich biosensor has been designed and successfully developed using an aptamer bioreceptor immobilized onto a screen-printed electrode surface for Mycobacterium tuberculosis (M. tuberculosis) detection in clinical sputum samples. In the sensing strategy, a CFP10-ESAT6 binding aptamer was immobilized onto a graphene/polyaniline (GP/PANI)-modified gold working electrode by covalent binding via glutaraldehyde linkage. Upon interaction with the CFP10-ESAT6 antigen target, the aptamer will capture the target where the nano-labelled $\mathrm{Fe}_{3} \mathrm{O}_{4} / \mathrm{Au}$ MNPs conjugated antibody is used to complete the sandwich format and enhance the signal produced from the aptamer-antigen interaction. Using this strategy, the detection of CFP10-ESAT6 antigen was conducted in the concentration range of 5 to $500 \mathrm{ng} / \mathrm{mL}$. From the analysis, the detection limit was found to be $1.5 \mathrm{ng} / \mathrm{mL}$, thereby demonstrating the efficiency of the aptamer as a bioreceptor. The specificity study was carried out using bovine serum albumin (BSA), MPT64, and human serum, and the result demonstrated good specificity that is $7 \%$ higher than the antibody-antigen interaction reported in a previous study. The fabricated aptasensor for M. tuberculosis analysis shows good reproducibility with an relative standard deviation (RSD) of $2.5 \%$. Further analysis of $M$. tuberculosis in sputum samples have shown good correlation with the culture method with $100 \%$ specificity and sensitivity, thus making the aptasensor a promising candidate for $M$. tuberculosis detection considering its high specificity and sensitivity with clinical samples.

Keywords: portable detection systems; electrochemical aptasensor; Mycobacterium tuberculosis; CFP10-ESAT6; differential pulse voltammetry (DPV); iron/gold magnetic nanoparticles

\section{Introduction}

Biosensors play a vital role in a plethora of applications, especially in the medical and food industrires, which comprise of the detection and quantification of proteins in clinical and food samples. Biosensors are described as the analytical devices used to detect the presence or quantify the concentration of a biological analyte by transducing the biochemical reactions of a bioreceptor with a specific target analyte into an optical, thermal or electrical signal [1]. Among different types of biosensors, electrochemical biosensors 
are of particular interest because of the lower limit of detection, simplicity, and easily miniaturized characteristics [2-4].

Bioreceptors are one of the key factors for explicit biosensor performance. Aptamers are single-stranded DNA or RNA sequences (most recently, peptides) that are generally less than hundred bases long [5]. Since their discovery in the 1990s, aptamers have received extensive interest for their application in biosensor development as an alternative to antibodies, which act as bioreceptors [6]. In general, the aptamers have to be isolated from the pools of random nucleic acid sequences by systematic evolution of ligands by an exponential enrichment (SELEX) process $[7,8]$. To specifically bind to their target, aptamers must fold into particular three-dimensional structures. Aptamers have been synthetically designed against a wide variety of targets, from small human molecules and viral proteins to whole microorganisms [9]. As compared to antibodies, aptamers are relatively easy to produce at a low cost, have high affinity towards their target and are generally stable $[6,10]$. On the other hand, aptamers can be synthesized in a large quantity with high reproducibility and purity [11]. A number of aptamer-based sensors have been developed using different transducer techniques and have demonstrated their excellent performance, which validates the promising potential of aptasensors [12-14].

Tuberculosis (TB) is one of the most common causes of death for those with human immunodeficiency virus (HIV), and this is due to the Mycobacterium tuberculosis (M. tuberculosis) pathogen [15]. This contagious disease is classified as airborne because it can be transmitted to other people when the infected person spews the bacteria into the air by coughing, sneezing, or even talking [16]. This pathogen's main route of infection is through the respiratory system and will further travel into the body towards the lungs. Other than the lungs, this bacterium can become active and spread to other parts of the body when the immune system becomes weak. Globally, the number of reported TB cases increased from 6.4 million in 2017 to 7.1 million in 2019 [17]. In Malaysia, the number of TB cases are high, with a current estimated incidence of 92 cases per 100,000 population during the year 2019 [17]. This is due to the high influx of illegal immigration, HIV, drug resistance, delayed diagnosis, high smoking rates, and diabetes [18-21]. Therefore, early and accurate detection of TB will be of great help to isolate patients and curb the spread of the disease.

The aptamer used in this study is specifically designed with a high affinity towards M. tuberculosis through the SELEX process. It is used as the bioreceptor immobilized on the working electrode surface to specifically detect various biomarkers of $M$. tuberculosis such as CFP10 [22], ESAT6 [23], CFP10-ESAT6 complex [9,13], Ag85A [24] and MPT64 [5,25]. In this study, CFP10-ESAT6 complex, an antigen secreted by M. tuberculosis, was chosen as a biomarker because of its better sensitivity compared to either CFP10 or ESAT6 antigen alone. Besides that, it is capable of avoiding false-positive results (better specificity) that usually happens due to a Bacillus Calmette-Guérin (BCG) vaccination [13]. Aptamer is widely known to be more selective than other commonly used antibody bioreceptors and this will increase the stability and robustness of the developed sensor.

Graphene (GP), in the form of a two-dimensional honeycomb, has a lot of useful properties such as a large surface area $\left(2630 \mathrm{~m}^{2} / \mathrm{g}\right)$, good electrical conductivity $\left(200,000 \mathrm{~cm}^{2} / \mathrm{Vs}\right)$ and good thermal conductivity of $\sim 5000 \mathrm{Wm} / \mathrm{K}$ [26]. It has been commonly used in biosensors due to its biocompatibility and non-toxic nature at optimal concentrations $[27,28]$. Meanwhile, polyaniline (PANI) is a conductive polymer that has been widely used because of its easy preparation process and low cost. In electrochemical sensors, PANI is reported to have fast electron transfer and excellent electrochemical activity [29]. Therefore, the combination of GP and PANI could enhance the conductivity on the surface of the working electrode in our proposed electrochemical biosensors, thus enhancing the signal transduction during biomolecule immobilization and detection [30]. This GP/PANI combination forms nanoparticle clusters on the working electrode's surface and hence offers a high surface area to volume ratio for biorecognition of molecules immobilized as compared to direct immobilization on the working electrode [31]. The 
optimum surface immobilization could also contribute to the high-performance detection of the disease.

Signal amplification via sandwich-type electrochemical antibodies or aptamer-based assays can be achieved by using labelling tracers such as enzymes and nanoparticles (NPs). This method is commonly used to obtain high detection sensitivity along with the improvements in the selectivity. This limits the crosstalk and interfering signal [32]. The various types of nanomaterials have been investigated as labels, particularly metal NPs due to their high stability compared to enzymatic signal tags [33,34]. Besides, they also have a high surface area to volume ratio that could anchor a large number of biomolecules, which then enables a much higher signal response [35].

In recent years, gold NPs (AuNPs) have been widely used as a label in biosensing technologies due to their advantages. Different detection schemes implementing AuNPs as labels have been reported, such as the direct electrooxidation of $\mathrm{Au}$ (III) and a two-step detection scheme. A two-step detection scheme involves the pre-oxidation of $\mathrm{Au}^{0}$ to $\mathrm{Au}$ (III) by dissolution in acidic medium or $\mathrm{HBr} / \mathrm{Br}_{2}$ mixture followed by stripping voltammetry detection or the direct reduction of the released $\mathrm{Au}(\mathrm{III})$ to $\mathrm{Au}^{0}$. The determination of AuNPs labels using electrochemical oxidation in hydrochloric acid $(\mathrm{HCl})$ is the most common method in electrochemical biosensors [34,36]. In this detection approach, the AuNPs undergo the electrochemical oxidation process in order to form $\mathrm{AuCl}_{4}{ }^{-}$, which is called the pre-oxidation step. Then, the $\mathrm{AuCl}_{4}{ }^{-}$formed is immediately reduced to metallic gold $\left(\mathrm{AuCl}_{4}{ }^{-}+3 \mathrm{e}^{-} \rightarrow \mathrm{Au}^{0}+4 \mathrm{Cl}^{-}\right)$and measured by voltammetric techniques, usually by differential pulse voltammetry (DPV) or square wave voltammetry (SWV). However, the acidity of $\mathrm{HCl}$ used needs to be evaluated since the use of highly acidic solutions contributes to the denaturation of biological material when used in decentralized settings [37]. Meanwhile, the performance of AuNPs could be enhanced by combination with magnetic NPs (MNPs). A work by Freitas et al. has shown that MNPs help to easily separate the target analyte from large and complex samples using an external magnetic field as well as enhance the reaction signal produced due to the high catalytic activity of MNP [38,39].

In this study, we proposed a sandwich-type electrochemical aptasensor for the detection of M. tuberculosis with modifications on the screen-printed gold electrode (SPGE) using iron/gold MNPs ( $\mathrm{Fe}_{3} \mathrm{O}_{4} / \mathrm{Au} \mathrm{MNPs}$ ) as a label, while the GP/PANI nanocomposite serves as a signal amplification layer. The DPV technique was used to detect the CFP10-ESAT6 antigen. It was measured by the direct electrooxidation of gold in a neutral medium to form $\mathrm{Au}(\mathrm{III})$ ions. As compared with other sensors used for M. tuberculosis detection, this aptasensor is more specific in its choice of target.

\section{Materials and Methods}

\subsection{Reagents}

The aptamer sequence used in this work is $5^{\prime}-\mathrm{NH}_{2}-\mathrm{GCC}$ TGT TGT GAG CCT CCT AAC CCC ATC TTA TAC GTA TAT GGA CTC ATC TCG ACC CCC GAT AGG CTT GGT ACA TGC TTA TTC TTG TCT CCC-3'. The aptamer was purchased from Integrated DNA Technologies (Coralville, Iowa, US). M. tuberculosis CFP10-ESAT6 antigen and polyclonal antibody $(\mathrm{Ab})$ were obtained from Cusabio (Houston, TX, USA). Bovine serum albumin (BSA), potassium hexacyanoferrate (III) $\left(\mathrm{K}_{3}\left[\mathrm{Fe}(\mathrm{CN})_{6}\right]\right)$, potassium chloride $(\mathrm{KCl}), 2$-mercaptoethanol (ME), 12-mercaptododecanoic acid (MDDA), (3-aminopropyl)triethoxysilane (APTES) and glutaraldehyde were all acquired from SigmaAldrich (St. Louis, MO, USA). Ethanol and sodium hydroxide $(\mathrm{NaOH})$ were purchased from HmbG Chemicals (Hamburg, Germany) and R\&M Chemicals (Essex, UK), respectively. All chemicals are of standard qualitative analytical grade. The aqueous solutions were prepared using ultrapure water unless otherwise specified. All cyclic voltammetry (CV) measurements were performed in $1 \mathrm{mM} \mathrm{K}_{3}\left[\mathrm{Fe}(\mathrm{CN})_{6}\right]$ with $50 \mathrm{mM} \mathrm{KCl}$. Differential pulse voltammetry (DPV) measurements were carried out in $0.1 \mathrm{M}$ phosphate-buffered saline (PBS) with pH 7.4. 0.5 M of sulphuric acid (Sigma, St. Louis, MO, USA) was used 
to activate the SPGE before further modification. Real samples (sputum) used for testing were collected by Hospital Universiti Sains Malaysia (HUSM), Kelantan, Malaysia.

\subsection{Instrumentation}

An Eco Chemie Autolab PGSTAT302 benchtop potentiostat with a NOVA 1.5 module (Metrohm, Utrecht, the Netherlands) was used for the electrochemical immunoassay analysis while a portable reader (DRP-DROPCAST, DropSens, Oviedo, Spain) was used for the on-site clinical sample analysis. A screen-printed gold electrode (SPGE) was purchased from DropSens, Spain. It consists of a working electrode (WE) and counter electrode (CE) that are made of gold ink, while the reference electrode is made of silver/silver chloride $(\mathrm{Ag} / \mathrm{AgCl})$. All of these electrodes were printed on a ceramic support. Other equipment used included circular dichroism (CD) (Jasco, Portland, OR, USA), X-ray diffraction (XRD) (X'Pert-MPD, PHILIPS, Amsterdam, Netherlands), high-resolution transmission electron microscopy (HR-TEM) (JEOL, Akishima, Japan), and field emission scanning electron microscopy (FESEM) (NOVA NANOSEM 230, FEI, Hillsboro, OR, USA).

\subsection{Preparation of $\mathrm{Fe}_{3} \mathrm{O}_{4} / \mathrm{Au} \mathrm{MNPs}$-Labelled Antibodies}

Iron oxide/gold magnetic nanoparticles $\left(\mathrm{Fe}_{3} \mathrm{O}_{4} / \mathrm{Au} \mathrm{MNPs}\right)$ were firstly prepared according to the previous protocol [31]. About $10 \mathrm{mg}$ of $\mathrm{Fe}_{3} \mathrm{O}_{4} / \mathrm{Au}$ MNPs was mixed with 2-mercaptoethanol and 12-mercaptododecanoic acid (ME-MDDA) (1 mM, 4:1) prior to conjugation with $\mathrm{Ab}$ and incubated in dark conditions for $24 \mathrm{~h}$. The functionalized $\mathrm{Fe}_{3} \mathrm{O}_{4} / \mathrm{Au}$ MNPs was washed several times with ethanol and water before being dispersed in 0.1 M PBS at pH 7.4. Then, the functionalized $\mathrm{Fe}_{3} \mathrm{O}_{4} / \mathrm{Au}$ MNPs were incubated for $2 \mathrm{~h}$ with $25 \mu \mathrm{g} / \mathrm{mL} \mathrm{Ab}$ followed by washing using PBS solution. Lastly, the bio-conjugated MNPs $\left(\mathrm{Fe}_{3} \mathrm{O}_{4} / \mathrm{Au}-\mathrm{Ab}\right)$ were blocked from non-specific binding by incubation with $1 \% \mathrm{BSA}$ $(2 \mathrm{~h})$ and washed to remove excess BSA several times using PBS solution.

\subsection{Electrochemical Aptamer-Based Assay Detection Scheme}

The development of aptasensor for CFP10-ESAT6 detection was conducted according to the previous study [9]; but with a different type of transducer. The WE surface of SPGE was electrochemically treated with $0.5 \mathrm{M} \mathrm{H}_{2} \mathrm{SO}_{4}$ using a $\mathrm{CV}$ technique (potential range: $0.0-1.6 \mathrm{~V}$, scan rate $100 \mathrm{mV} / \mathrm{s}$ ) followed by deposition of $4 \mu \mathrm{L}$ of $1 \mathrm{mg} / \mathrm{mL}$ GP/PANI onto the WE surface. The GP/PANI-modified SPGE was dried under room temperature overnight. Then, it was washed with ethanol to remove the unbound GP/PANI, followed by drying at $70{ }^{\circ} \mathrm{C}$ for $30 \mathrm{~min}$. The capture aptamer (CapApt) immobilization process on the electrode surface was conducted through a cross-linking reaction using glutaraldehyde. The modified SPGE was immersed in $1 \%$ glutaraldehyde for $30 \mathrm{~min}$ at $4{ }^{\circ} \mathrm{C}$. After the reaction, the modified electrode was rinsed with deionized water and dried at $37^{\circ} \mathrm{C}$. Then, $6 \mu \mathrm{L}$ CapApt $(20 \mu \mathrm{g} / \mathrm{mL})$ was dropped onto the electrode surface, left to react for an hour and washed using deionized water. The surface of electrode was blocked with $0.25 \%$ BSA for $1 \mathrm{~h}$ at $37^{\circ} \mathrm{C}$ to avoid non-specific binding. After washing with PBS washing buffer, the prepared electrode was incubated with $4 \mu \mathrm{L}$ of CFP10-ESAT6 antigen solution with different concentrations at $37^{\circ} \mathrm{C}$ for $1 \mathrm{~h}$. Finally, the prepared $\mathrm{Fe}_{3} \mathrm{O}_{4} / \mathrm{Au}-\mathrm{Ab}$ buffer solution $(4 \mu \mathrm{L})$ was dropped onto the electrode surface. After incubation for $40 \mathrm{~min}$ followed by washing, the electrode was ready for the practical measurements.

\subsection{Optimization of Experimental Conditions for the Bioreceptor}

The concentration and incubation time of CapApt immobilized on the GP/PANImodified SPGE were optimized to obtain the maximum performance of the aptasensor. The concentration of CapApt was tested in the range of 5 to $100 \mu \mathrm{g} / \mathrm{mL}$ with a constant concentration of CFP10-ESAT6 $(20 \mathrm{ng} / \mathrm{mL})$ immobilized on the electrode. The binding of CapApt and CFP10-ESAT6 was evaluated at various times ranging from 30 to $150 \mathrm{~min}$. The binding was monitored by measuring the change in the oxidation current using DPV in 0.1 M PBS (pH 7.4) solution as described above. 


\subsection{Detection Study}

The CapApt/GP/PANI-modified SPGE surface was incubated in different concentrations ( 5 to $500 \mathrm{ng} / \mathrm{mL}$ ) of CFP10-ESAT6 for $1 \mathrm{~h}$, rinsed twice with PBS to remove unspecific adsorbed CFP10-ESAT6 molecules and the response was recorded with DPV taken in $0.1 \mathrm{M}$ PBS ( $\mathrm{pH} 7.4$ ) at the potential range of 0.0 to $1.0 \mathrm{~V}$.

\subsection{Specificity and Reproducibility Studies}

For specificity studies, the sensor was incubated with $20 \mathrm{ng} / \mathrm{mL}$ CFP10-ESAT6, $2.5 \mathrm{mg} / \mathrm{mL}$ BSA (widely distinct protein), $20 \mathrm{ng} / \mathrm{mL}$ MPT64 (secreted by M. tuberculosis as well) and $10 \times$ dilution human serum for $1 \mathrm{~h}$. After washing using PBS, $\mathrm{Fe}_{3} \mathrm{O}_{4} / \mathrm{Au}-\mathrm{Ab}$ was dropped on the surface of the electrode and incubated for $40 \mathrm{~min}$ to complete the assay. The current response of different analytes was analysed using DPV by immersing the prepared electrodes in $0.1 \mathrm{M} \mathrm{PBS}(\mathrm{pH} 7.4)$ at a potential ranging from 0.0 to $1.0 \mathrm{~V}$. Meanwhile, for the reproducibility study, five individual electrodes were prepared for $20 \mathrm{ng} / \mathrm{mL}$ CFP10-ESAT6 antigen detection. After incubating the antigen for $1 \mathrm{~h}$, the electrode was further incubated with $\mathrm{Fe}_{3} \mathrm{O}_{4} / \mathrm{Au}-\mathrm{Ab}$ to complete the assay. The DPV was measured to evaluate the reproducibility performance of the developed sensor.

\subsection{Real Sample (Sputum) Analysis}

Hospital Universiti Sains Malaysia (HUSM), Kelantan, Malaysia supplied 10 samples collected from patients. The patients were diagnosed with TB using the standard method of smear microscopy and a culture test to validate our developed electrochemical aptasensor. A culture test is a confirmation test for TB detection in hospitals in Malaysia. The results from the culture method will be used as a reference, while the performance of smear microscopy will be compared with the developed electrochemical aptasensor. The analysis was carried out at the laboratory of Medical Microbiology and Parasitology, HUSM. The clinical samples (sputum) were diluted in $4 \% \mathrm{NaOH}$ prior to detection [40]. Decontaminated samples were dropped on the modified SPGE and incubated for $1 \mathrm{~h}$; for the testing, at least $4 \mu \mathrm{L}$ of decontaminated sample is required. After that, $4 \mu \mathrm{L}$ of $\mathrm{Fe}_{3} \mathrm{O}_{4} / \mathrm{Au}-\mathrm{Ab}$ was dropped onto the electrode and incubated for another $40 \mathrm{~min}$. Finally, the electrode was immersed in 0.1 M PBS (pH 7.4) and ready for the measurements using a portable reader. The data displayed a value in the unit of $\mu \mathrm{A}$. This whole process is shown in Figure 1.

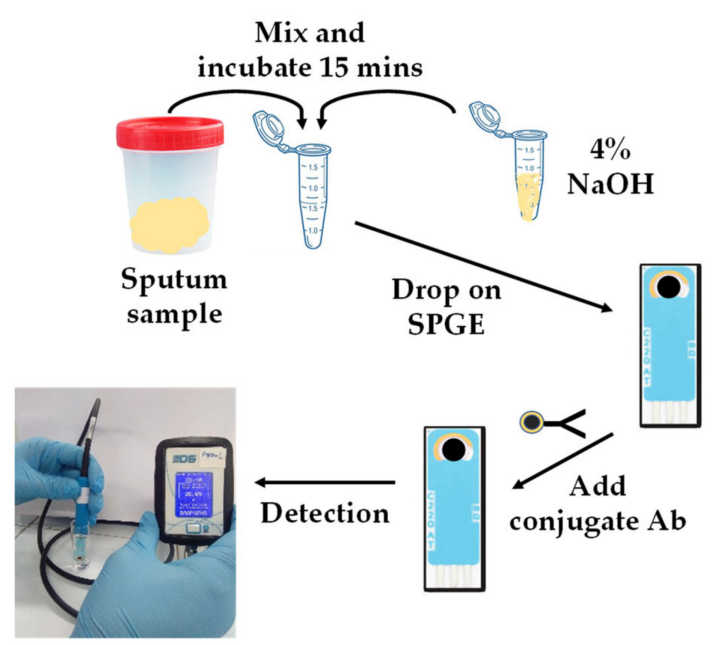

Figure 1. Sputum sample analysis for CFP10-ESAT6 antigen using portable readers. (i) The sample was decontaminated in $4 \% \mathrm{NaOH}$ for $15 \mathrm{~min}$ and dropped onto the surface of modified electrode, (ii) $\mathrm{Fe}_{3} \mathrm{O}_{4} / \mathrm{Au}-\mathrm{Ab}$ was dropped after the treated sample incubated on the capture aptamer (CapApt)/ graphene (GP)/polyaniline (PANI) / screen-printed gold electrode (SPGE) surface for $40 \mathrm{~min}$, and (iii) the prepared electrode was ready for measurements using portable reader. 


\section{Results and Discussion}

\subsection{Aptamer-Antibody Sandwich Interaction}

As described in the experimental section, the aptamer was covalently immobilized on the working electrode surface to act as a capture probe for CFP10-ESAT6 protein. The selection of aptamer is based on a previous study [9], which developed the sequence of an aptamer for a CFP10-ESAT6 antigen. The structure of the aptamer is shown in Figure 2a. Beforehand, CD characterization was performed to confirm the binding and determine the conformational changes of CFP10-ESAT6 antigen and its aptamer. The CD is usually used for molecules such as nucleic acids and proteins containing chiral atoms. It measures differential absorption of left and right polarized light by the analytes [41,42]. As shown in Figure 2b, CFP10-ESAT6 antigen alone has a negative peak at $218 \mathrm{~nm}$. Significant changes in the antigen structure were observed upon addition of CapApt to CFP10-ESAT6 antigen, indicating that aptamer folding occurred due to binding interactions.
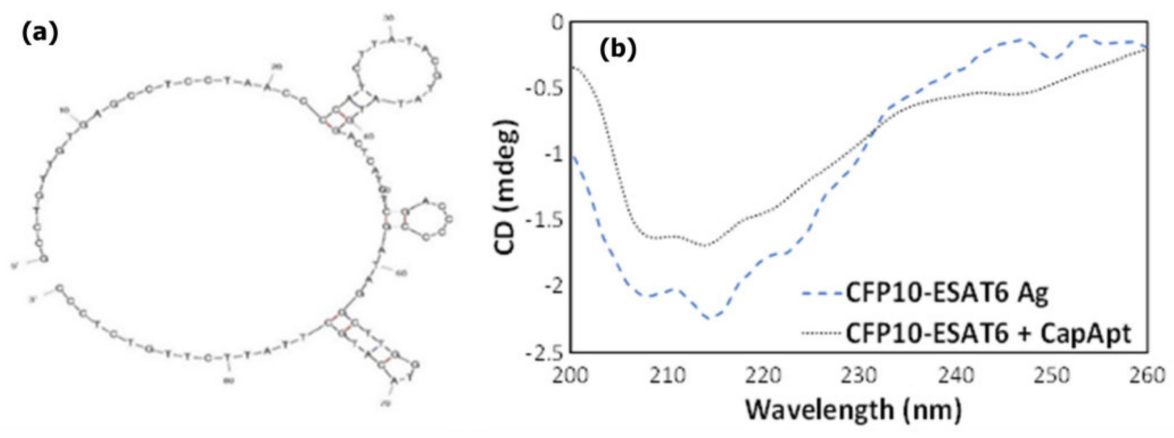

Figure 2. (a) Structure of capture aptamer for CFP10-ESAT6 antigen. (b) circular dichroism (CD) analysis indicates structural changes due to binding interaction between capture aptamer and CFP10ESAT6 antigen.

Figure 3a illustrates the different steps involved in the fabrication of a biosensor for the detection of CFP10-ESAT6 based on its specific bioreceptor by an aptamer-antibody assay. The covalent immobilization was conducted through a glutaraldehyde crosslinking reaction on the GP/PANI-modified SPGE surface. Figure $3 b$ shows the field emission scanning electron microscope (FESEM) images of GP/PANI nanocomposite. The image of the GP/PANI nanocomposite showed that the GP sheets were mostly covered by PANI nanotubes and formed porous structures. This indicates that the presence of GP promoted the formation of agglomerated PANI nanofibers. The effect of the GP/PANI modification electrode surface has been elaborated in the Supplementary Materials (Section S2). Then, this step was followed by a blocking step with BSA to avoid non-specific adsorption on the transducer surface. Then, the $\mathrm{Ab}$ that was conjugated with $\mathrm{Fe}_{3} \mathrm{O}_{4} / \mathrm{Au}$ MNPs was deposited on the sensing platform to enhance the detection signal through sandwich type detection. Figure $3 c$ shows the TEM images of the $\mathrm{Fe}_{3} \mathrm{O}_{4} / \mathrm{Au}$ MNPs that were used as nanoparticle labelling to increase the signal produced from the aptamer-antigen interaction. The average particles of $\mathrm{Fe}_{3} \mathrm{O}_{4} / \mathrm{Au}$ MNPs are around $35 \mathrm{~nm}$, the molecular d-spacing was calculated from Image J software, which resulted in around $0.25 \mathrm{~nm}$ for the lighter part (iron core) and around $0.23 \mathrm{~nm}$ for the darker part (gold shell). The lattice distances measured for the shell correspond to the known Au lattice parameters for the (111) plane and those measured for the core match well the $\mathrm{Fe}_{3} \mathrm{O}_{4}$ lattice parameters for the (3 11 1) plane [43]. Preparation and crystalline structure characterization of this material have been further evaluated in the Supplementary Materials (Section S1). Finally, the biosensor was immersed in a PBS buffer solution of $\mathrm{pH} 7.4$ and CFP10-ESAT6 was determined by differential pulse voltammetry of the generated $\mathrm{AuCl}_{4}{ }^{-}$as the reaction product. 
(a)
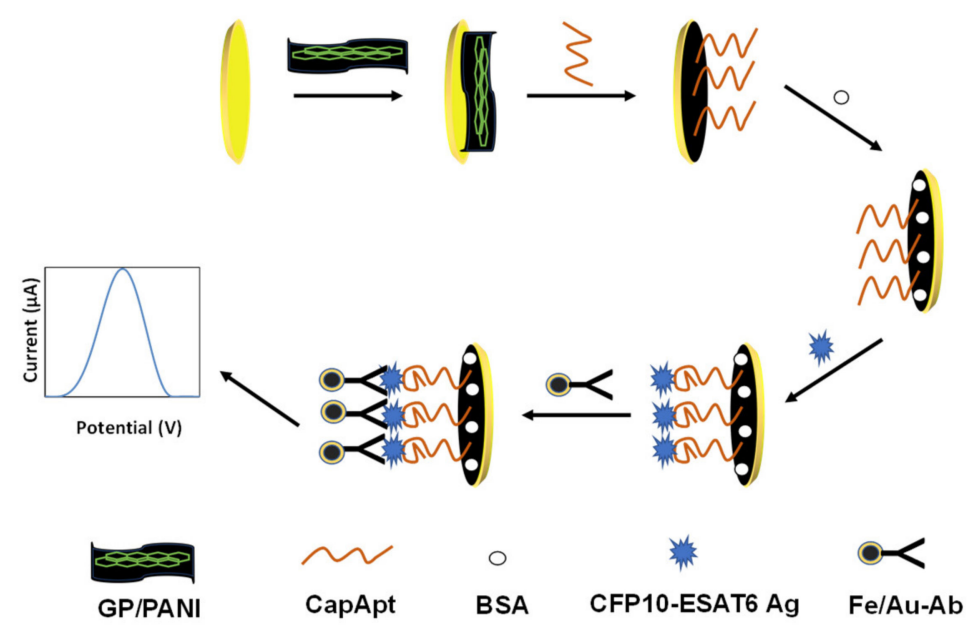

(b)

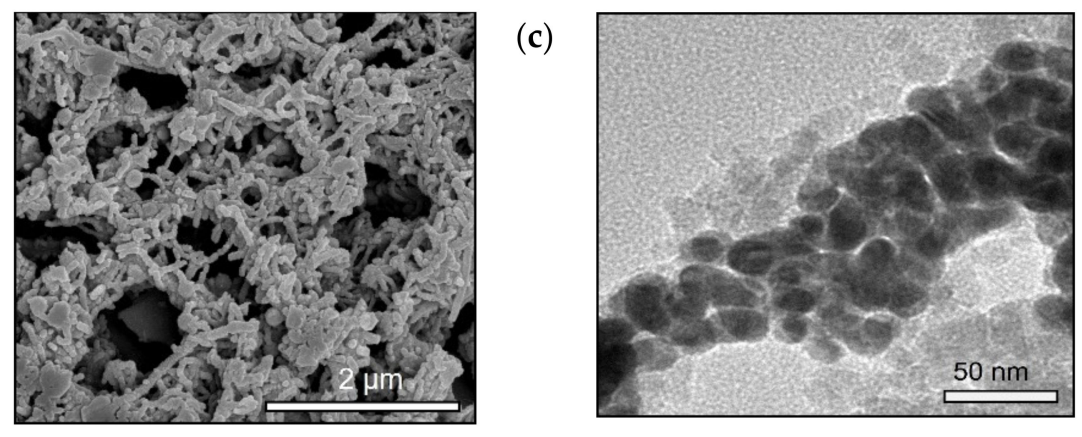

Figure 3. (a) Schematic flow of the electrochemical aptamer-based assay showing (i) modification of SPGE surface with GP/PANI, (ii) CapApt immobilization on GP/PANI-modified screenprinted gold electrode (SPGE), (iii) blocking by bovine serum albumin (BSA) to prevent non-specific binding, (iv) CFP10-ESAT6 antigen immobilization on CapApt/GP/PANI/SPGE surface, and (v) $\mathrm{Fe}_{3} \mathrm{O}_{4} / \mathrm{Au}-\mathrm{Ab}$ immobilization on CFP10-ESAT6/CapApt/GP/PANI/SPGE surface. (b) GP/PANI nanocomposite structure and (c) $\mathrm{Fe}_{3} \mathrm{O}_{4} / \mathrm{Au}$ MNPs structure.

\subsection{Optimization Studies of Aptasensor}

Optimization steps are very important and necessary to construct a good, stable, and reproducible biosensor. For this purpose, capture probe deposition parameters such as concentration of CapApt as well as incubation time of CapApt were examined. These conditions need to be optimized, as they influence the binding of the capturing probe with CFP10-ESAT6 antigen and affect the peak current of DPV. Different concentrations of CapApt $(5,20,40,60,80$, and $100 \mu \mathrm{g} / \mathrm{mL})$ were studied by drop casting them onto GP/PANI-modified SPGE for $2 \mathrm{~h}$ so that the optimum concentration of CapApt bonding on the sensor could be determined. As seen in Figure $4 \mathrm{a}$, the peak current increased with an increase in CapApt concentration ( 5 to $20 \mu \mathrm{g} / \mathrm{mL}$ ). Nevertheless, the peak current started to decrease as the concentration increased from 40 to $100 \mu \mathrm{g} / \mathrm{mL}$. This might be due to the over saturation of CapApt on the surface of GP/PANI-modified SPGE, which made CapApt less effective at binding with target antigens. Hence, the concentration of CapApt that was chosen to be used in further study is $20 \mu \mathrm{g} / \mathrm{mL}$ instead of $5 \mu \mathrm{g} / \mathrm{mL}$. Besides, $20 \mu \mathrm{g} / \mathrm{mL}$ CapApt concentration provides better reproducibility as compared to $5 \mu \mathrm{g} / \mathrm{mL}$. Figure $4 \mathrm{~b}$ shows the effect of CapApt incubation time on peak current. From the results, the peak current reached the maximum peak at $60 \mathrm{~min}$. Upon extending the incubation time, the current slowly dropped, which might be due to the instability of CapApt left at $37^{\circ} \mathrm{C}$ for a longer time on the electrode surface. In general, the incubation time of $60 \mathrm{~min}$ is sufficient to record the detection of CFP10-ESAT6 antigen. 

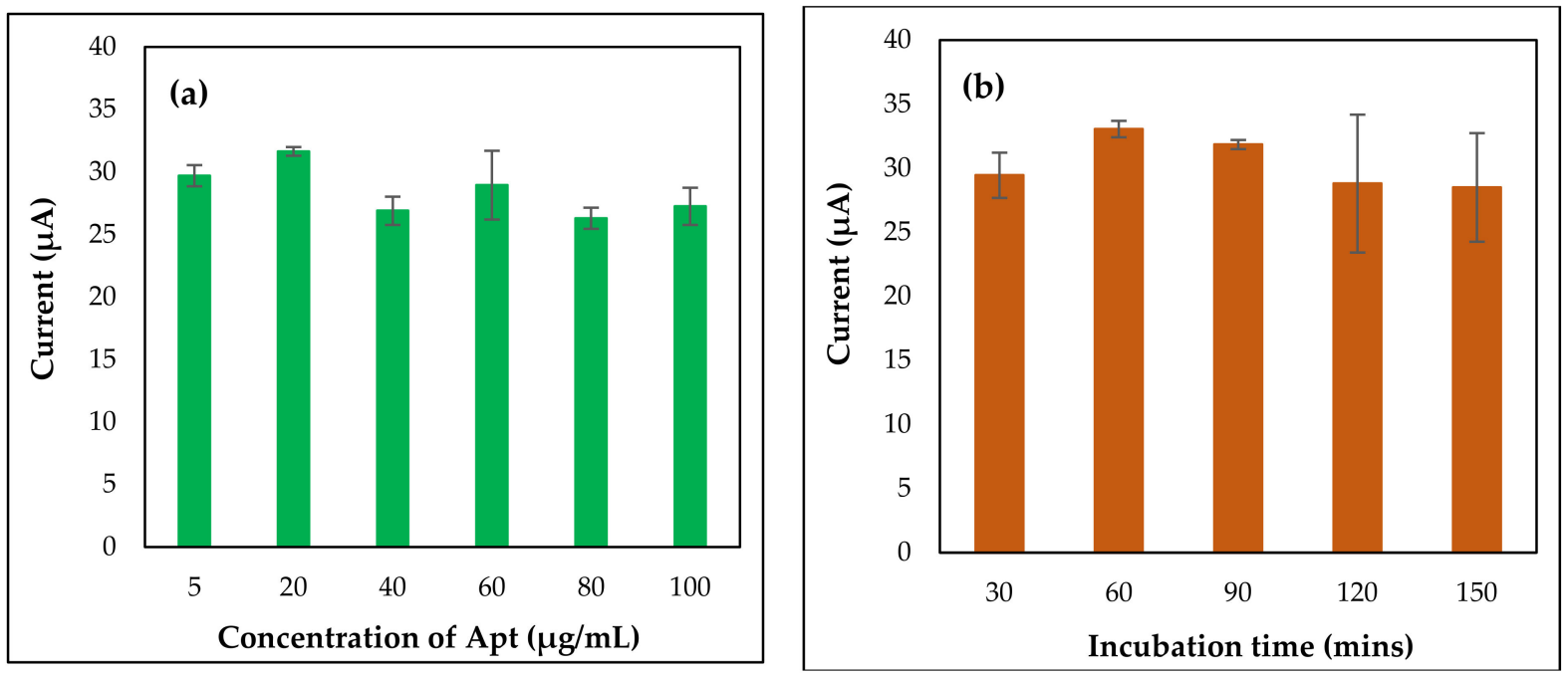

Figure 4. The effect of different concentrations (a) and immobilization time (b) of CapApt on the fabricated aptasensor in $0.1 \mathrm{M}$ PBS at potential 0.0-1.0 V.

\subsection{Limit of Detection (LOD), Specificity, and Reproducibility}

Different concentrations of CFP10-ESAT6 antigen were detected by utilizing a specific constructed aptasensor. The analytical performance of our modified electrode was studied by using one of the most sensitive electrochemical analysis techniques, known as DPV. Figure 5a shows the current response of aptasensor upon interaction with the $\mathrm{Fe}_{3} \mathrm{O}_{4} / \mathrm{Au}$ MNPs conjugated $\mathrm{Ab}$ used for the detection of CFP10-ESAT6. It was shown that, with an increase in CFP10-ESAT6 concentration, the current response of $\mathrm{Fe}_{3} \mathrm{O}_{4} / \mathrm{Au}$ MNPs increased. This indicates an elevated interaction between $\mathrm{Ab}$ and antigen as the amount of $\mathrm{Fe}_{3} \mathrm{O}_{4} / \mathrm{Au}$ MNPs conjugated $\mathrm{Ab}$ increases.

A linear relationship between the analytical responses, $\Delta I / I_{0} \%$ signal and the logarithmic values of CFP10-ESAT6 concentration was found within the concentration of CFP10-ESAT6 ranging from $5-500 \mathrm{ng} / \mathrm{mL}$ as shown in Figure $5 \mathrm{~b} . \Delta I / I_{0} \%$ indicating; $I_{0}=$ Peak current for blank $(0 \mathrm{ng} / \mathrm{mL}$ CFP10-ESAT6), I = current response for certain concentration and $\Delta I=I-I_{0}$. The graph indicates an increase in sensor response signal with that of increased CFP10-ESAT6 concentration, which generated a linear positive slope. The calibration plot was fitted to a linear equation:

$$
\mathrm{y}=\mathrm{mx}+\mathrm{c}
$$

where $\mathrm{y}$ is the $\Delta \mathrm{I} / \mathrm{I}_{0} \%$ signal, $\mathrm{m}$ is the gradient slope and $\mathrm{c}$ is the $\mathrm{y}$-intercept. The aptasensor exhibited a linear regression, expressed as $\mathrm{y}=10.54 \mathrm{x}+0.53$ with a correlation coefficient of $R^{2}=0.9948$. The LOD was obtained at $1.52 \mathrm{ng} / \mathrm{mL}$ of CFP10-ESAT6 concentration by using the $3 \sigma / \mathrm{s}$ calculation formula, where $\sigma$ is the standard deviation of the blank and $\mathrm{s}$ is the slope of the calibration curve (Figure $5 b$ ).

The specificity study was conducted to prove the biosensor response is specific between the CFP10-ESAT6 antigen and the capturing probes immobilized on the electrodes. The study was conducted using $20 \mathrm{ng} / \mathrm{mL}$ CFP10-ESAT6, $2.5 \mathrm{mg} / \mathrm{mL}$ BSA, $20 \mathrm{ng} / \mathrm{mL}$ MPT64 and 10x dilution of human serum. As portrayed in Figure 5c, the highest peak current for the sensor was shown by CFP10-ESAT6 antigen, while the other pathogens were detected at a low peak current. This is because the pathogens other than CFP10-ESAT6 were not captured by CapApt. The aptasensor showed that the current difference between CFP10-ESAT6 with other pathogens is about $15 \%$ or more. 

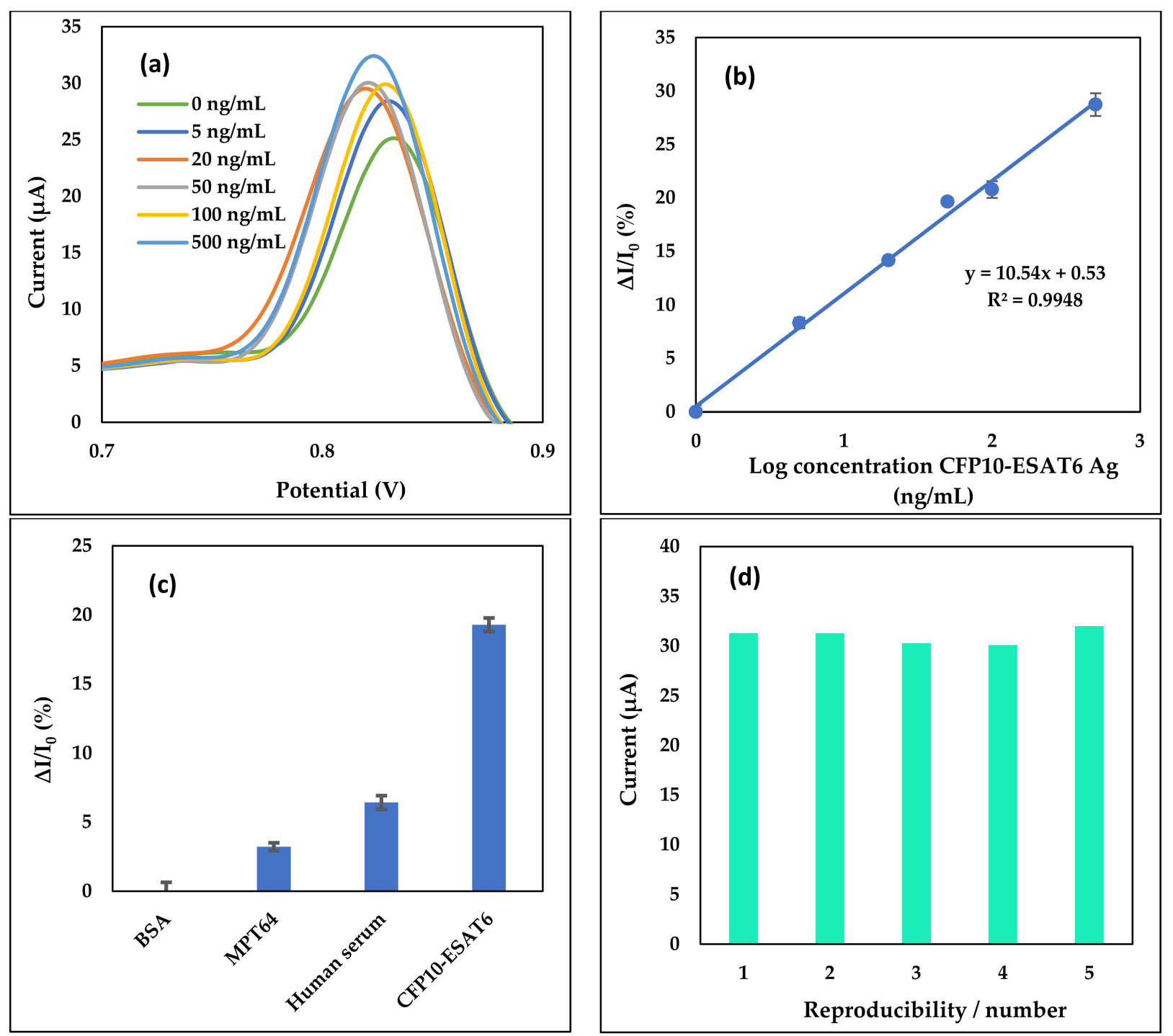

Figure 5. (a) differential pulse voltammetries (DPVs) of the aptasensor at different concentrations of CFP10-ESAT6 Ag, (b) the linear calibration plot of aptasensor in $0.1 \mathrm{M} \mathrm{PBS} \mathrm{(pH} \mathrm{7.4),} \mathrm{(c)} \mathrm{bar} \mathrm{graph} \mathrm{of} \mathrm{specificity} \mathrm{study} \mathrm{using} 2.5 \mathrm{mg} / \mathrm{mL}$ of BSA, $20 \mathrm{ng} / \mathrm{mL}$ of MPT64, 10× dilution of human serum and $20 \mathrm{ng} / \mathrm{mL}$ CFP10-ESAT6 using the developed aptasensor, and (d) bar graph of reproducibility study on aptasensor by using $20 \mathrm{ng} / \mathrm{mL}$ of CFP10-ESAT6 antigen in 0.1 M PBS at pH 7.4. Error bars show the standard deviations of replicate measurements.

The reproducibility of the developed aptasensor was evaluated by means of relative standard deviation (RSD). Five independently modified electrodes were prepared for the detection of $20 \mathrm{ng} / \mathrm{mL}$ CFP10-ESAT6 antigen. From the bar chart in Figure 5d, the peak current obtained from $20 \mathrm{ng} / \mathrm{mL}$ CFP10-ESAT6 antigen detection on the five different modified aptasensor electrodes resulted in a current value in the range of 30-31 $\mu \mathrm{A}$ with an RSD of $2.5 \%$. The consistency of signals recorded from the modified electrodes proved the reliability of the modification and stability of the detection process, thus showing its potential for mass production.

The analytical performance of the developed sensor for M. tuberculosis detection with other detection methods reported in the literature, together with the results, is shown in Table 1. Most of the detection was based on optical transduction techniques such as enzyme-linked immunosorbent assay (ELISA) [44,45], optical waveguide [46], fluorescence resonance energy transfer (FRET) [47], calorimetric magnetophoretic assay [48], and electrochemical sensor [49]. All of them except ELISA recorded a lower LOD when compared with our developed sensor, while our previous work recorded almost the same LOD. However, 
when compared with this work, the other methods still require multi-step amplification, are labour-intensive and time-consuming, and use heavy equipment, which obviously limit their use for point-of-care testing (POCT) for an extremely resource-limited environment. To the best of our knowledge, the electrochemical aptasensor that we developed in this work is capable of the direct detection of $M$. tuberculosis in sputum samples and can be implemented on POCT. Even though the LOD of our developed sensors was higher than several studies reported in Table 1, the LOD still falls in the physiological range of interest for M. tuberculosis, which is around $100 \mathrm{ng} / \mathrm{mL}$ in TB patients [20]. Besides that, our developed sensor can be easily miniaturized and transported for on-site detection during clinical application.

Table 1. Limit of detection (LOD) of different detection method for M. tuberculosis.

\begin{tabular}{|c|c|c|c|c|c|}
\hline Biomarkers & $\begin{array}{l}\text { Biorecognition } \\
\text { Elements }\end{array}$ & Detection Method & Detection Time & LOD & References \\
\hline CFP10 & Antibody & Plasmonic ELISA & $>9 \mathrm{~h}$ & $0.01 \mu \mathrm{g} / \mathrm{mL}$ & [44] \\
\hline MPT64 & Aptamer & ELISA & $>2 \mathrm{~h}$ & $0.5 \mathrm{mg} / \mathrm{mL}$ & [45] \\
\hline ESAT6 & & Waveguided- & & $100 \mathrm{pM}$ & \\
\hline $\begin{array}{l}\text { LAM } \\
\text { Ag85 }\end{array}$ & Antibody & $\begin{array}{l}\text { based optical } \\
\text { biosensor }\end{array}$ & $\sim 2 \mathrm{~h}$ & $\begin{array}{c}1 \mathrm{pM} \\
0.5 \mathrm{pM}\end{array}$ & [46] \\
\hline Ag85B & Antibody & $\begin{array}{c}\text { Fluorescence- } \\
\text { based } \\
\text { immunoassay }\end{array}$ & Not available & $13.0 \mathrm{pg} / \mathrm{mL}$ & [47] \\
\hline CFP10 & Antibody & $\begin{array}{l}\text { Calorimetric } \\
\text { magnetophoretic } \\
\text { immunoassay }\end{array}$ & $\sim 10 \mathrm{~min}$ & $10 \mathrm{pg} / \mathrm{mL}$ & [48] \\
\hline CFP10-ESAT6 & Antibody & $\begin{array}{c}\text { DPV } \\
\text { electrochemical }\end{array}$ & $\sim 2 \mathrm{~h}$ & $1.52 \mathrm{ng} / \mathrm{ml}$ & [49] \\
\hline CFP10-ESAT6 & Aptamer & $\begin{array}{c}\text { DPV } \\
\text { electrochemical }\end{array}$ & $\sim 2 \mathrm{~h}$ & $1.5 \mathrm{ng} / \mathrm{mL}$ & Present work \\
\hline
\end{tabular}

\subsection{Clinical Sputum Samples Detection}

A total of 10 sputum samples were analysed for clinical sample analysis. As the gold standard, results from the smear microscopy and culture method were used for comparison with our aptasensor reader. Each sample was identified as positive $(\mathrm{P})$ or negative $(\mathrm{N})$ according to the culture method (reference method). The culture method takes around 2-3 weeks to obtain the results, while smear microscopy takes around $15 \mathrm{~min}$. The detection time using our portable reader is $2 \mathrm{~h}$. From the reference method, it shows that there are six patients (out of 10) who were diagnosed positive and four were negative. From our portable reader, the results obtained were simplified in bar chart form as shown in Figure 6, where all of the positive samples show positive $\Delta I / I_{0} \%$ currents while the negative samples show negative $\Delta I / I_{0} \%$ currents.

Despite qualitative detection, this sandwich-type aptasensor is also able to quantify the concentration of CFP10-ESAT6 antigen in sputum samples, as shown in Table 2. By inserting the value of $\Delta I / I_{0} \%$ in a linear equation: $y=10.54 \log x+0.53$, the concentration of CFP10-ESAT6 antigen were able to be determined.

The sensitivity and specificity of the smear microscopy method and our portable reader were compared by using the culture method as a reference and is shown in Table 3. The results obtained for the sensitivity and specificity of the smear microscopy and aptasensor reader was identical, which are $100 \%$. From these findings, it was supported that our developed aptasensor is suitable for the detection of CFP10-ESAT6 antigen in sputum samples. 


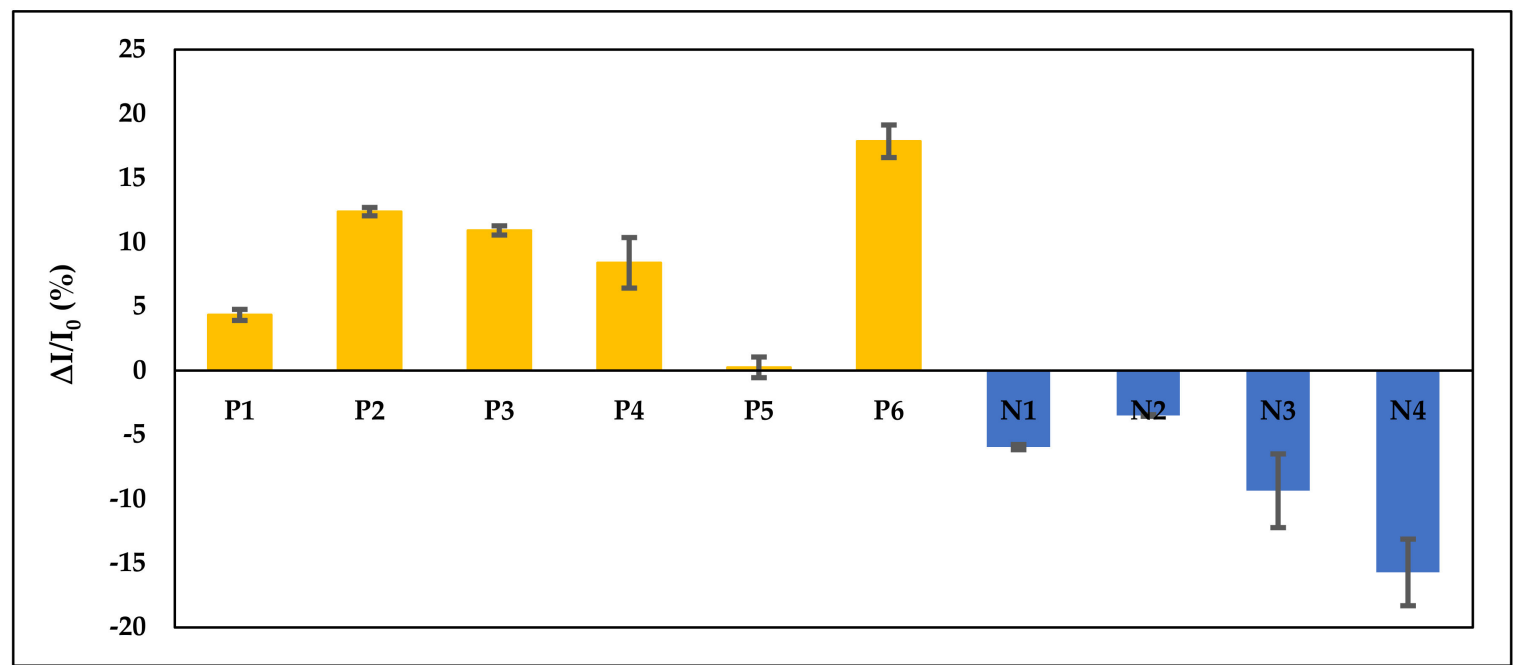

Figure 6. Current measured using portable reader from 10 clinical sputum samples immobilized on aptasensor. The results were identified as six positive $(\mathrm{P})$ samples and four negative $(\mathrm{N})$ samples, in accordance with the culture method.

Table 2. Comparison of various TB results from the culture method, smear microscopy, and portable aptasensor reader.

\begin{tabular}{cccc}
\hline No & $\begin{array}{c}\text { Concentration of } \\
\text { CFP10-ESAT6 Ag } \\
(\mathbf{n g} / \mathbf{m L})\end{array}$ & Culture Method & AFB Direct Smear \\
\hline P1 & 2.3 & Positive & Positive \\
P2 & 13.3 & Positive & Positive \\
P3 & 9.7 & Positive & Positive \\
P4 & 5.6 & Positive & Positive \\
P5 & 0.9 & Positive & Positive \\
P6 & 44.1 & Positive & Positive \\
N1 & & Negative & Negative \\
N2 & & Negative & Negative \\
N3 & & Negative & Negative \\
N4 & & Negative & Negative \\
\hline
\end{tabular}

Table 3. Sensitivity and specificity of smear microscopy and aptasensor methods used to identify M. tuberculosis in clinical sputum samples that were obtained from HUSM.

\begin{tabular}{ccccccc}
\hline Methods & $\begin{array}{c}\text { Positive } \\
\text { Samples }\end{array}$ & $\begin{array}{c}\text { Negative } \\
\text { Samples }\end{array}$ & $\begin{array}{c}\text { False-Negative } \\
\text { Samples }^{\mathbf{1}}\end{array}$ & $\begin{array}{c}\text { False-Positive } \\
\text { Samples }^{2}\end{array}$ & $\begin{array}{c}\text { Total } \\
\text { Specificity } \\
\mathbf{( \% )}\end{array}$ & $\begin{array}{c}\text { Sensitivity } \\
\mathbf{( \% )}\end{array}$ \\
\hline $\begin{array}{c}\text { Culture } \\
\text { (Reference) }\end{array}$ & 6 & 4 & & & 10 & \\
$\begin{array}{c}\text { Smear } \\
\text { microscopy }\end{array}$ & 6 & 4 & 0 & 0 & 10 & 100 \\
$\begin{array}{c}\text { Aptasensor } \\
\text { reader }\end{array}$ & 6 & 4 & 0 & 0 & 10 & 100 \\
\hline
\end{tabular}

${ }^{1}$ When a patient being diagnosed as negative but the bacteria are actually present, ${ }^{2}$ When a person who is not actually sick is diagnosed as positive.

\section{Conclusions}

In this study, a sandwich type electrochemical aptasensor was designed for the detection of the M. tuberculosis antigen biomarker, CFP10-ESAT6. The SPGE was modified with GP/PANI for the immobilization of the capturing probe (CapApt). Meanwhile, $\mathrm{Fe}_{3} \mathrm{O}_{4} / \mathrm{Au}$ MNPs were used as a label to amplify the signal generation. The $\mathrm{Fe}_{3} \mathrm{O}_{4} / \mathrm{Au}$ MNPs were conjugated with primary antibodies to complete the sandwich format. The analytical 
performances of both sensors were successfully conducted by direct electrooxidation of AuNPs in PBS solution to form $\mathrm{AuCl}_{4}{ }^{-}$due to the presence of chloride ions measured by DPV. It was found that the signal generated increased as the concentration of CFP10-ESAT6 antigen increased. The developed aptasensor was evaluated through the detection of tuberculosis in sputum samples and demonstrated $100 \%$ sensitivity and specificity. This suggests promising performance for the aptasensor and the commercialization of the aptasensor for TB and other diseases' detection should be considered for early and effective illness prevention.

Supplementary Materials: The following are available online at https://www.mdpi.com/article/10 $.3390 /$ nano11092446/s1, Figure S1: HR-TEM images of (a) $\mathrm{Fe}_{3} \mathrm{O}_{4}$ MNPs and (b) $\mathrm{Fe}_{3} \mathrm{O}_{4} / \mathrm{Au}$ MNPs dispersed in water and dried on copper grid, Figure S2: XRD patterns of $\mathrm{Fe}_{3} \mathrm{O}_{4}$ MNPs and $\mathrm{Fe}_{3} \mathrm{O}_{4} / \mathrm{Au}$ MNPs, Figure S3: FESEM images of (a) bare SPGE and (b) GP/PANI-modified SPGE, Figure S4: (a) Cyclic voltammograms and (b) Nyquist plots of bare SPGE, PANI-modified SPGE and GP/PANImodified SPGE in $1 \mathrm{mM}\left[\mathrm{Fe}(\mathrm{CN})_{6}\right]^{3-/ 4-}$ solution containing $50 \mathrm{mM} \mathrm{KCl}$. Parameter for $\mathrm{CV}$ : Potential range: $-0.4-0.6 \mathrm{~V}$; Scan rate: $100 \mathrm{mV} / \mathrm{s}$. Parameter for EIS: Frequency range: $0.01 \mathrm{~Hz}-100 \mathrm{kHz}$.

Author Contributions: Conceptualization, U.Z.M.A. and N.A.Y.; investigation, U.Z.M.A.; resources, S.S., F.M. and H.A.A.-L.; writing—original draft preparation, U.Z.M.A.; writing-review and editing, F.N.M.F., F.M. and S.K.K.; supervision, N.A.Y., J.A., S.A.A.A. and N.H.A.R.; project administration and funding acquisition, N.A.Y. and H.A.A.-L. All authors have read and agreed to the published version of the manuscript.

Funding: This research was funded by the Malaysia Research University Network (MRUN) [UPM/ 800-4/11/MRUN/2018/5539230] and the Putra Grant-Putra Graduate Initiative (GP-IPS) under Universiti Putra Malaysia [9528600]. The KSU authors were funded by the Researchers Supporting Project (RSP-2021/355), King Saud University, Riyadh, Saudi Arabia.

Institutional Review Board Statement: The study was conducted according to the guidelines of the Declaration of Helsinki, and approved by the Medical Research and Ethics Committee of Ministry of Health, Malaysia (NMRR-17-3001-39473 and 27 January 2018).

Informed Consent Statement: Informed consent was obtained from all subjects involved in the study.

Data Availability Statement: The data presented in this study are available on request from the corresponding author.

Acknowledgments: The authors would like to thank the medical laboratory technologist at Hospital Universiti Sains Malaysia for their help with storing and handling the sputum samples. We would also like to thank Universiti Putra Malaysia for the project funding. The King Saud University authors acknowledge the funding from Researchers Supporting Project number (RSP-2021/355), King Saud University, Riyadh, Saudi Arabia.

Conflicts of Interest: The authors declare no conflict of interest.

\section{References}

1. Srivastava, S.K.; van Rijn, C.J.M.; Jongsma, M.A. Biosensor-based detection of tuberculosis. RSC Adv. 2016, 6, 17759-17771. [CrossRef]

2. Golichenari, B.; Nosrati, R.; Farokhi-Fard, A.; Faal Maleki, M.; Gheibi Hayat, S.M.; Ghazvini, K.; Vaziri, F.; Behravan, J. Electrochemical-based biosensors for detection of Mycobacterium tuberculosis and tuberculosis biomarkers. Crit. Rev. Biotechnol. 2019, 39, 1056-1077. [CrossRef] [PubMed]

3. Tufa, L.T.; Oh, S.; Tran, V.T.; Kim, J.; Jeong, K.J.; Park, T.J.; Kim, H.J.; Lee, J. Electrochemical immunosensor using nanotriplex of graphene quantum dots, $\mathrm{Fe}_{3} \mathrm{O}_{4}$ and $\mathrm{Ag}$ nanoparticles for tuberculosis. Electrochim. Acta 2018, 290, 369-377. [CrossRef]

4. Zhao, D.; Yu, G.; Tian, K.; Xu, C. A highly sensitive and stable electrochemical sensor for simultaneous detection towards ascorbic acid, dopamine, and uric acid based on the hierarchical nanoporous PtTi alloy. Biosens. Bioelectron. 2016, 82, 119-126. [CrossRef] [PubMed]

5. Thakur, H.; Kaur, N.; Sareen, D.; Prabhakar, N. Electrochemical determination of M. tuberculosis antigen based on poly (3,4ethylenedioxythiophene) and functionalized carbon nanotubes hybrid platform. Talanta 2017, 171, 115-123. [CrossRef] [PubMed]

6. Zhou, L.; Li, D.J.; Gai, L.; Wang, J.P.; Li, Y. Bin Electrochemical aptasensor for the detection of tetracycline with multi-walled carbon nanotubes amplification. Sens. Actuators B Chem. 2012, 162, 201-208. [CrossRef]

7. Tuerk, C.; Gold, L. Systematic evolution of ligands by exponential enrichment: RNA ligands to bacteriophage T4 DNA polymerase. Science 1990, 249, 505-510. [CrossRef] 
8. Ellington, A.D.; Szostak, J.W. In vitro selection of RNA molecules that bind specific ligands. Nature 1990, 346, 818-822. [CrossRef] [PubMed]

9. Rotherham, L.S.; Maserumule, C.; Dheda, K.; Theron, J.; Khati, M. Selection and Application of ssDNA Aptamers to Detect Active TB from Sputum Samples. PLoS ONE 2012, 7, e46862. [CrossRef] [PubMed]

10. Mishra, G.K.; Sharma, V.; Mishra, R.K. Electrochemical aptasensors for food and environmental safeguarding: A review. Biosensors 2018, 8, 28. [CrossRef]

11. Sypabekova, M.; Jolly, P.; Estrela, P.; Kanayeva, D. Electrochemical aptasensor using optimized surface chemistry for the detection of Mycobacterium tuberculosis secreted protein MPT64 in human serum. Biosens. Bioelectron. 2019, 123, 141-151. [CrossRef]

12. Ahmad Raston, N.H.; Nguyen, V.T.; Gu, M.B. A new lateral flow strip assay (LFSA) using a pair of aptamers for the detection of Vaspin. Biosens. Bioelectron. 2017, 93, 21-25. [CrossRef] [PubMed]

13. He, F.; Xiong, Y.; Liu, J.; Tong, F.; Yan, D. Construction of Au-IDE/CFP10-ESAT6 aptamer/DNA-AuNPs MSPQC for rapid detection of Mycobacterium tuberculosis. Biosens. Bioelectron. 2016, 77, 799-804. [CrossRef]

14. Fatin, M.F.; Rahim Ruslinda, A.; Gopinath, S.C.B.; Arshad, M.K.M. High-performance interactive analysis of split aptamer and HIV-1 Tat on multiwall carbon nanotube-modified field-effect transistor. Int. J. Biol. Macromol. 2019, 125, 414-422. [CrossRef]

15. Zhou, L.; He, X.; He, D.; Wang, K.; Qin, D. Biosensing technologies for mycobacterium tuberculosis detection: Status and new developments. Clin. Dev. Immunol. 2011, 2011, 193963. [CrossRef]

16. Nurmalasari, R.; Gaffar, S.; Hartati, Y.W. Label-Free Electrochemical DNA Biosensor for the Detection of Mycobacterium tuberculosis using Gold Electrode Modified by Self-Assembled Monolayer of Thiol. Procedia Chem. 2015, 17, 111-117. [CrossRef]

17. World Health Organization. Global Tuberculosis Report 2020; World Health Organization: Geneva, Switzerland, 2020.

18. Mat Zaid, M.H.; Abdullah, J.; Yusof, N.A.; Sulaiman, Y.; Wasoh, H.; Md Noh, M.F.; Issa, R. PNA biosensor based on reduced graphene oxide/water soluble quantum dots for the detection of Mycobacterium tuberculosis. Sens. Actuators B Chem. 2017, 241, 1024-1034. [CrossRef]

19. World Health Organization. Global Tuberculosis Report 2015; World Health Organization: Geneva, Switzerland, 2015.

20. Mohd Bakhori, N.; Yusof, N.A.; Abdullah, J.; Wasoh, H.; Ab Rahman, S.K.; Abd Rahman, S.F. Surface enhanced CdSe/ZnS QD/SiNP electrochemical immunosensor for the detection of Mycobacterium tuberculosis by combination of CFP10-ESAT6 for better diagnostic specificity. Materials 2020, 13, 149. [CrossRef] [PubMed]

21. William, T.; Parameswaran, U.; Lee, W.K.; Yeo, T.W.; Anstey, N.M.; Ralph, A.P. Pulmonary tuberculosis in outpatients in Sabah, Malaysia: Advanced disease but low incidence of HIV co-infection. BMC Infect. Dis. 2015, 15, 1-9. [CrossRef]

22. Tang, X.L.; Zhou, Y.X.; Wu, S.M.; Pan, Q.; Xia, B.; Zhang, X.L. CFP10 and ESAT6 aptamers as effective Mycobacterial antigen diagnostic reagents. J. Infect. 2014, 69, 569-580. [CrossRef] [PubMed]

23. Li, L.; Yuan, Y.; Chen, Y.; Zhang, P.; Bai, Y.; Bai, L. Aptamer based voltammetric biosensor for Mycobacterium tuberculosis antigen ESAT-6 using a nanohybrid material composed of reduced graphene oxide and a metal-organic framework. Microchim. Acta 2018, 185, 379. [CrossRef]

24. Ansari, N.; Ghazvini, K.; Ramezani, M.; Shahdordizadeh, M.; Yazdian-Robati, R.; Abnous, K.; Taghdisi, S.M. Selection of DNA aptamers against Mycobacterium tuberculosis Ag85A, and its application in a graphene oxide-based fluorometric assay. Microchim. Acta 2018, 185, 1-8. [CrossRef] [PubMed]

25. Bai, L.; Chen, Y.; Bai, Y.; Chen, Y.; Zhou, J.; Huang, A. Fullerene-doped polyaniline as new redox nanoprobe and catalyst in electrochemical aptasensor for ultrasensitive detection of Mycobacterium tuberculosis MPT64 antigen in human serum. Biomaterials 2017, 133, 11-19. [CrossRef] [PubMed]

26. Krishnan, S.K.; Singh, E.; Singh, P.; Meyyappan, M.; Nalwa, H.S. A review on graphene-based nanocomposites for electrochemical and fluorescent biosensors. RSC Adv. 2019, 9, 8778-8781. [CrossRef]

27. Zheng, D.; Vashist, S.K.; Al-Rubeaan, K.; Luong, J.H.T.; Sheu, F.S. Mediatorless amperometric glucose biosensing using 3aminopropyltriethoxysilane-functionalized graphene. Talanta 2012, 99, 22-28. [CrossRef]

28. Shao, Y.; Wang, J.; Wu, H.; Liu, J.; Aksay, I.A.; Lin, Y. Graphene based electrochemical sensors and biosensors: A review. Electroanalysis 2010, 22, 1027-1036. [CrossRef]

29. Shoaie, N.; Daneshpour, M.; Azimzadeh, M.; Mahshid, S.; Khoshfetrat, S.M.; Jahanpeyma, F.; Gholaminejad, A.; Omidfar, K.; Foruzandeh, M. Electrochemical sensors and biosensors based on the use of polyaniline and its nanocomposites: A review on recent advances. Microchim. Acta 2019, 186, 1-29. [CrossRef]

30. Kong, F.; Gu, S.; Li, W.; Chen, T.; Xu, Q.; Wang, W. A paper disk equipped with graphene/polyaniline/Au nanoparticles/glucose oxidase biocomposite modified screen-printed electrode: Toward whole blood glucose determination. Biosens. Bioelectron. 2014, 56, 77-82. [CrossRef]

31. Mohd Azmi, U.Z.; Yusof, N.A.; Kusnin, N.; Abdullah, J.; Suraiya, S.; Ong, P.S.; Ahmad Raston, N.H.; Abd Rahman, S.F.; Mohamad Fathil, M.F. Sandwich electrochemical immunosensor for early detection of tuberculosis based on graphene/polyaniline-modified screen-printed gold electrode. Sensors 2018, 18, 3926. [CrossRef]

32. Duangkaew, P.; Tapaneeyakorn, S.; Apiwat, C.; Dharakul, T. Ultrasensitive electrochemical immunosensor based on dual signal amplification process for $\mathrm{p} 16^{\mathrm{INK} 4 \mathrm{a}}$ cervical cancer detection in clinical samples. Biosens. Bioelectron. 2015, 74, 673-679. [CrossRef]

33. Wei, Q.; Xiang, Z.; He, J.; Wang, G.; Li, H.; Qian, Z.; Yang, M. Dumbbell-like Au-Fe ${ }_{3} \mathrm{O}_{4}$ nanoparticles as label for the preparation of electrochemical immunosensors. Biosens. Bioelectron. 2010, 26, 627-631. [CrossRef] 
34. Idegami, K.; Chikae, M.; Kerman, K.; Nagatani, N.; Yuhi, T.; Endo, T.; Tamiya, E. Gold nanoparticle-based redox signal enhancement for sensitive detection of human chorionic gonadotropin hormone. Electroanalysis 2008, 20, 14-21. [CrossRef]

35. Lim, S.A.; Yoshikawa, H.; Tamiya, E.; Yasin, H.M.; Ahmed, M.U. A highly sensitive gold nanoparticle bioprobe based electrochemical immunosensor using screen printed graphene biochip. RSC Adv. 2014, 4, 58460-58466. [CrossRef]

36. Leng, C.; Lai, G.; Yan, F.; Ju, H. Gold nanoparticle as an electrochemical label for inherently crosstalk-free multiplexed immunoassay on a disposable chip. Anal. Chim. Acta 2010, 666, 97-101. [CrossRef] [PubMed]

37. Cho, I.H.; Lee, J.; Kim, J.; Kang, M.S.; Paik, J.K.; Ku, S.; Cho, H.M.; Irudayaraj, J.; Kim, D.H. Current technologies of electrochemical immunosensors: Perspective on signal amplification. Sensors 2018, 18, 207. [CrossRef] [PubMed]

38. Freitas, M.; Viswanathan, S.; Nouws, H.P.A.; Oliveira, M.B.P.P.; Delerue-Matos, C. Iron oxide/gold core/shell nanomagnetic probes and CdS biolabels for amplified electrochemical immunosensing of Salmonella typhimurium. Biosens. Bioelectron. 2014, 51, 195-200. [CrossRef]

39. Zheng, N.; Stucky, G.D. A general synthetic strategy for oxide-supported metal nanoparticle catalysts. J. Am. Chem. Soc. 2006, 128, 14278-14280. [CrossRef] [PubMed]

40. Steingart, K.R.; Ng, V.; Henry, M.; Hopewell, P.C.; Ramsay, A.; Cunningham, J.; Urbanczik, R.; Perkins, M.D.; Aziz, M.A.; Pai, M. Sputum processing methods to improve the sensitivity of smear microscopy for tuberculosis: A systematic review. Lancet Infect. Dis. 2006, 6, 664-674. [CrossRef]

41. Azri, F.A.; Eissa, S.; Zourob, M.; Chinnappan, R.; Sukor, R.; Yusof, N.A.; Raston, N.H.A.; Alhoshani, A.; Jinap, S. Electrochemical determination of zearalenone using a label-free competitive aptasensor. Microchim. Acta 2020, 187, 1-10. [CrossRef]

42. Ocaña, C.; Hayat, A.; Mishra, R.; Vasilescu, A.; Del Valle, M.; Marty, J.L. A novel electrochemical aptamer-antibody sandwich assay for lysozyme detection. Analyst 2015, 140, 4148-4153. [CrossRef]

43. Chauhan, R.; Basu, T. Functionalised Au Coated Iron Oxide Nanocomposites Based Reusable Immunosensor for AFB1 Detection. J. Nanomater. 2015, 2015, 1-16. [CrossRef]

44. Mohd Bakhori, N.; Yusof, N.A.; Abdullah, J.; Wasoh, H.; Md Noor, S.S.; Ahmad Raston, N.H.; Mohammad, F. Immuno Nanosensor for the Ultrasensitive Naked Eye Detection of Tuberculosis. Sensors 2018, 18, 1932. [CrossRef] [PubMed]

45. Qin, L.; Zheng, R.; Ma, Z.; Feng, Y.; Liu, Z.; Yang, H.; Wang, J.; Jin, R.; Lu, J.; Ding, Y.; et al. The selection and application of ssDNA aptamers against MPT64 protein in Mycobacterium tuberculosis. Clin. Chem. Lab. Med. 2009, 47, 405-411. [CrossRef] [PubMed]

46. Mukundan, H.; Kumar, S.; Price, D.N.; Ray, S.M.; Lee, Y.; Min, S.; Eum, S.; Kubicek-sutherland, J.; Resnick, J.M.; Grace, W.K.; et al. Rapid detection of Mycobacterium tuberculosis biomarkers in a sandwich immunoassay format using a waveguide-based optical biosensor. Tuberculosis 2012, 92, 407-416. [CrossRef]

47. Kim, E.J.; Kim, E.B.; Lee, S.W.; Cheon, S.A.; Kim, H.J.; Lee, J.; Lee, M.K.; Ko, S.; Park, T.J. An easy and sensitive sandwich assay for detection of Mycobacterium tuberculosis Ag85B antigen using quantum dots and gold nanorods. Biosens. Bioelectron. 2017, 87, 150-156. [CrossRef] [PubMed]

48. Kim, J.; Lee, J.; Lee, K.I.; Park, T.J.; Kim, H.J.; Lee, J. Rapid monitoring of CFP-10 during culture of Mycobacterium tuberculosis by using a magnetophoretic immunoassay. Sens. Actuators B Chem. 2013, 177, 327-333. [CrossRef]

49. Mohd Azmi, U.Z.; Yusof, N.A.; Abdullah, J.; Alang Ahmad, S.A.; Mohd Faudzi, F.N.; Ahmad Raston, N.H.; Suraiya, S.; Ong, P.S.; Krishnan, D.; Sahar, N.K. Portable electrochemical immunosensor for detection of Mycobacterium tuberculosis secreted protein CFP10-ESAT6 in clinical sputum samples. Microchim. Acta 2021, 188, 1-11. [CrossRef] 